Polybrominated Diphenyl Ethers in the Sediments of the Great Lakes. 2

\title{
Lakes Michigan and Huron
}

(Song, et al.)
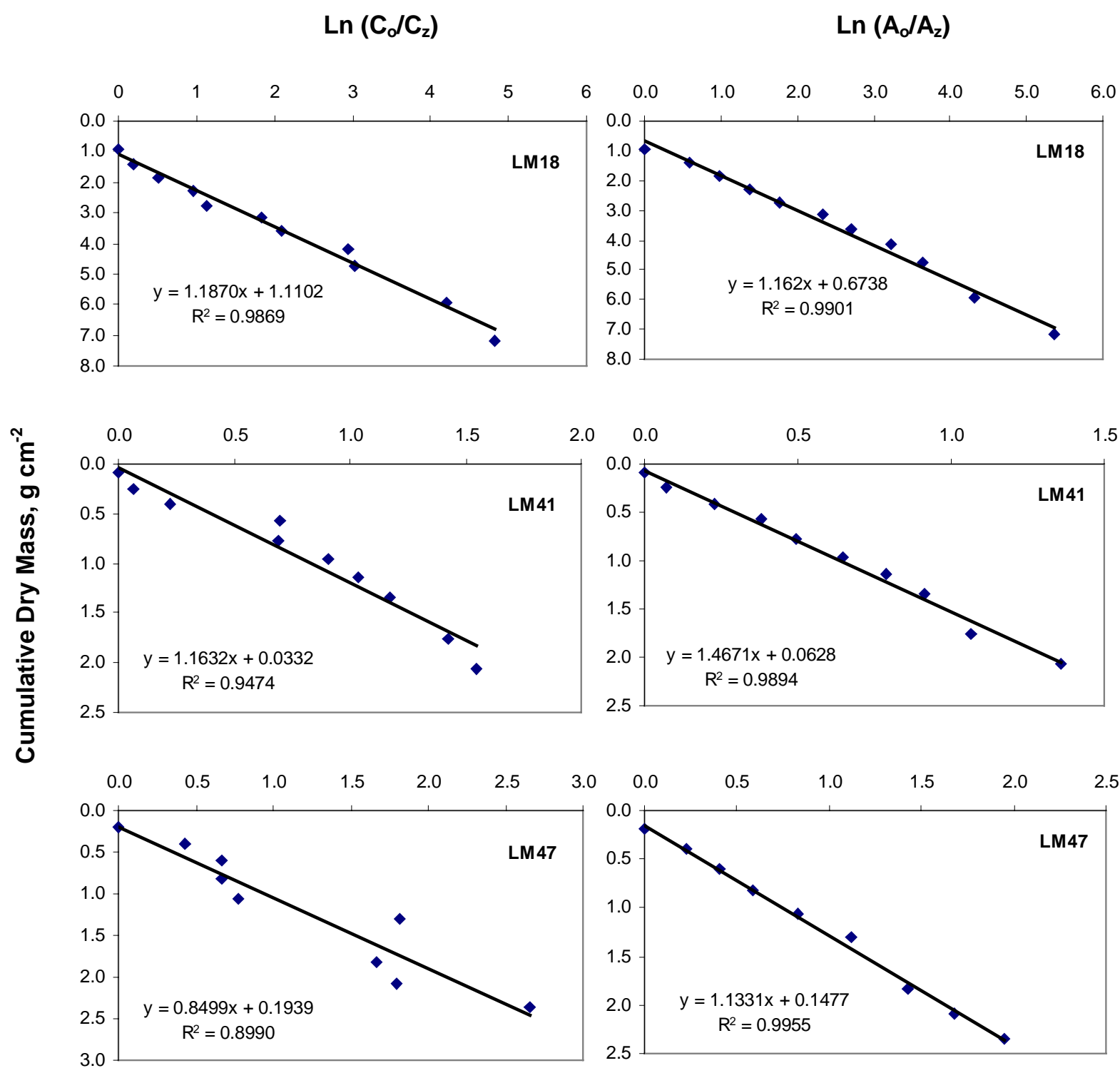

FIGURE S1. Activity of ${ }^{210} \mathrm{~Pb}$ vs. Cumulative Dry Mass of Sediment in Lake Michigan. 

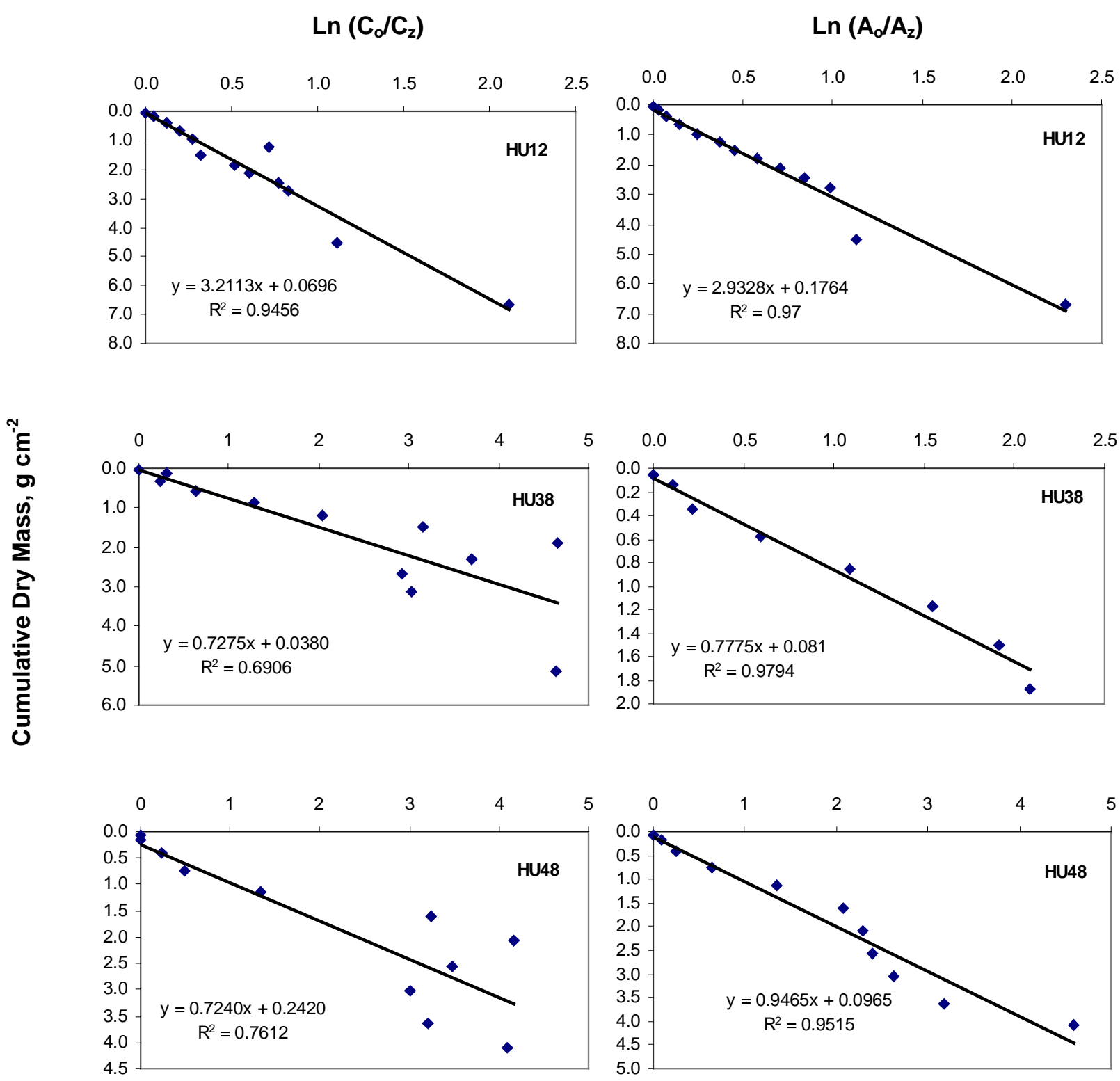

FIGURE S2. Activity of ${ }^{210} \mathrm{~Pb}$ vs. Cumulative Dry Mass of Sediment in Lake Huron.

$\mathrm{C}_{\mathrm{z}}=$ unsupported ${ }^{210} \mathrm{~Pb}$ activity $\left(\mathrm{dpm} \mathrm{g}^{-1}\right)$ in the core segment at depth $\mathrm{z}$,

$\mathrm{C}_{\mathrm{o}}=$ unsupported ${ }^{210} \mathrm{~Pb}$ activity $\left(\mathrm{dpm} \mathrm{g}^{-1}\right)$ in the surface segment,

$\mathrm{A}_{\mathrm{z}}=$ the integrated unsupported ${ }^{210} \mathrm{~Pb}$ activity $\left(\mathrm{dpm} \mathrm{cm} \mathrm{cm}^{-2}\right)$ in the core below depth $\mathrm{z}$,

$\mathrm{A}_{\mathrm{o}}=$ the integrated unsupported ${ }^{210} \mathrm{~Pb}$ activity $\left(\mathrm{dpm} \mathrm{cm}{ }^{-2}\right)$ in the entire core.

The sedimentation rate is calculated using the equation

Sedimentation Rate $\left(\mathrm{g} \mathrm{cm}^{-2} \mathrm{yr}^{-1}\right)=$ Slope $\times 0.693 / 22.26$

where 22.26 (yr) is the half life of ${ }^{210} \mathrm{~Pb}$. 